\title{
SÍNDROME DE CÁNCER HEREDITARIO DE MAMA Y OVARIO: APLICACIÓN CLÍNICA
}

\section{Hereditary breast and ovarian cancer syndrome: Clinical application}

\author{
Laura Yuriko González-Teshima ${ }^{1}$; Fabio Samir Vargas-Cely ${ }^{1}$; \\ Juan Sebastián Muñoz-Sandoval, $M^{2}$; Julián Ramírez-Cheyne, $M D^{3}$; \\ Wilmar Saldarriaga-Gil, $M D, M S c^{4}$
}

Recibido: marzo 16/15 - Aceptado: febrero 22/16

\section{RESUMEN}

Objetivo: aportar al ginecólogo herramientas para la identificación de pacientes con riesgo de síndrome de cáncer hereditario de mama y ovario $(\mathrm{SCH}-$ $\mathrm{MO})$, y brindar consejería en el manejo preventivo de pacientes con este síndrome.

Materiales y métodos: a partir de un caso hipotético se formulan preguntas relacionadas con el riesgo de desarrollar cáncer de mama y ovario en pacientes con SCHMO. Para responder estas preguntas se realizó una revisión de la literatura pertinente en las bases de datos Medline vía PubMed, ScienceDirect y SciELO. Se utilizaron los términos MESH "Síndrome de cáncer de mama y ovario hereditario", "Neoplasias ováricas”, "Neoplasias de la mama", "Genes BRCA1", "Genes BRCA2" y su equivalente en inglés. Los resultados se restringieron a artículos publicados entre el 2005 y 2015. Resultados: a través de la búsqueda en PubMed se

1 Estudiante de Medicina y Cirugía, Universidad del Valle, Cali (Colombia).

2 Médico, Universidad del Valle, Cali (Colombia).

3 Profesor Asistente, Universidad del Valle, aspirante a Magíster en Ciencias Biomédicas con énfasis Genética Médica, Universidad del Valle, Cali (Colombia)

4 Ginecoobstetra, Maestría en Ciencias Básicas Médicas, EmbriologíaGenética. Profesor Titular, Departamentos de Morfología y Ginecoobstetricia. Universidad del Valle, Hospital Universitario del Valle, Cali (Colombia).wilmar.saldarriaga@correounivallle.edu.co obtuvieron 56 artículos, de los cuales se seleccionaron 45. En ScienceDirect y SciELO se encontraron 7 artículos. Además, se incluyeron 4 artículos de fuentes no ligadas a estas bases de datos.

Conclusiones: el ginecoobstetra debe identificar pacientes con riesgo de presentar el síndrome de cáncer hereditario de mama y ovario, y explicar a los pacientes la importancia de la realización de las pruebas moleculares de los genes BRCA1 y BRCA2 y de participar en equipos multidisciplinarios que además deben incluir al genetista, cirujano, los oncólogos y al paciente para la toma de decisiones médicas de acuerdo con los resultados moleculares.

Palabras clave: síndrome de cáncer de mama y ovario hereditario, neoplasias ováricas, neoplasias de la mama, genes BRCA1, genes BRCA2.

\section{ABSTRACT}

Objective: To provide gynaecologists with tools for the identification of patients at risk of hereditary breast and ovarian cancer syndrome (HBOC) and present advise regarding the preventive management of patients with this syndrome.

Materials and methods: Questions were asked in relation to the risk of patients with HBOC developing breast and ovarian cancer. To answer those questions, a review of the relevant literature 
was conducted in the Medline database via PubMed, and in ScienceDirect and SciELO. The MESH terms used were Breast and Ovarian Cancer Syndrome, Ovarian Neoplasms, Breast Neoplasms, BRCA1 Genes, BRCA2 Genes, and their equivalent in English. Results were limited to articles published between 2005 and 2015.

Results: Overall, 56 articles were found in PubMed, of which 45 were selected. The search in ScienceDirect and SciELO resulted in 7 articles. Additionally, 4 articles from other sources not linked to these data bases were also included.

Conclusions: Obstetric gynaecologists must identify patients at risk of presenting Hereditary Breast and Ovarian Cancer Syndrome, and explain to the patients the importance of performing molecular testing for BRCA1 and BRCA2 genes; and they must participate in multi-disciplinary teams consisting also of geneticists, surgeons, oncologists and patients for medical decision-making in accordance with the molecular results.

Key words: Hereditary breast and ovarian cancer syndrome, ovarian neoplasms, breast neoplasms, BRCA1 and BRCA2 Genes.

\section{INTRODUCCIÓN}

El síndrome de cáncer hereditario de mama y ovario (SCHMO) es una condición que aumenta la probabilidad de desarrollar cáncer de mama, ovario y de otros tipos de cáncer como páncreas y próstata, debido a la presencia de mutaciones germinales en los genes de susceptibilidad BRCA1 o BRCA2 localizados en el cromosoma 17q21 (1) y 13q12 - q13 (2) respectivamente (3-6).

La gran mayoría de mutaciones en el cáncer ocurre en órganos diferenciados (mutaciones somáticas) y no son heredables; aproximadamente del 5 al $10 \%$ de todos los cánceres humanos se deben a mutaciones heredables y suelen presentarse en individuos genéticamente relacionados, confiriéndoles una susceptibilidad aumentada a ciertos cánceres específicos. A estas entidades se les ha denominado síndromes de cáncer hereditario (7).
El cáncer de mama es el segundo tipo de cáncer más común entre las mujeres colombianas (8) y el más frecuente entre las mujeres del mundo, representando la tercera causa de mortalidad por cáncer a nivel global (9). El cáncer de ovario es el séptimo cáncer más común entre las mujeres del mundo y es la quinta causa de mortalidad por cáncer entre este grupo (10).

Entre el 5 y $10 \%$ de los cánceres de mama y ovario son hereditarios $(11,12)$. De los cánceres de mama hereditarios, hasta el $50 \%$ se debe a mutaciones en BRCA1 y el $40 \%$ en BRCA2. De los cánceres de ovario hereditarios el $90 \%$ se debe a mutaciones en BRCA1 y entre el 5 al $10 \%$ en BRCA2 $(12,13)$. Así, con el análisis genético y molecular del SCHMO se han establecido programas dirigidos de detección temprana, tamizaje y prevención, lo que justifica en primera instancia el abordaje y estudio genético de los pacientes (14).

La importancia del conocimiento sobre SCHMO para la práctica clínica del ginecoobstetra radica en el hecho de ser el especialista de primera línea de consulta para pacientes con los tipos de cáncer implicados en el síndrome. Además, dada la masificación de la información médica a través de medios electrónicos, con mayor frecuencia llegan pacientes a la consulta con preguntas específicas sobre su riesgo de tener cáncer dada su historia familiar o personal, otros que solicitan se les hagan pruebas moleculares como los BRCA 1 y 2 o ya con los resultados para ser interpretados. Dados todos estos interrogantes que se pueden presentar en la consulta del ginecólogo, este debe tener información actualizada para orientar de forma pertinente al paciente.

Este documento tiene como objetivos aportar al ginecoobstetra herramientas para la identificación de pacientes con riesgo de SCHMO, y brindar consejería en el manejo preventivo de pacientes con este síndrome.

\section{ESCENARIO}

Paciente de 35 años quien consulta a control ginecológico ya que dos tías maternas han presentado 
cáncer de seno y unas amigas le indicaron que hay una prueba genética que puede hacer el diagnóstico del cáncer antes de que aparezca. Otros antecedentes de importancia son: 3 gestaciones, 2 partos, 1 aborto; lactó a los hijos por dos años, y ha planificado con anticonceptivos orales por tres años. $\mathrm{Al}$ examen se encuentran senos sin alteraciones, sin masas o secreciones por el pezón.

Se hace diagnóstico de adulta sana y alto riesgo de cáncer de seno. Usted le explica que la encuentra sana, que le va a solicitar una ecografía de seno y que no considera que se requieran más exámenes por el momento. Ella le solicita que por favor le pida la prueba genética y otros exámenes que le aseguren que no tiene cáncer de seno. Ante esta solicitud usted le pide la prueba de los genes BRCA 1 y BRCA 2.

El ginecólogo se hace las siguientes preguntas: ¿qué riesgo tienen los pacientes con SCHMO de desarrollar cáncer? ¿Cómo realizar un diagnóstico adecuado? ¿Cuándo se deben solicitar las pruebas? ¿Cómo interpretar los resultados con prueba positiva para alguna de las mutaciones en los genes BRCA1 o BRCA2?

\section{MATERIALES Y MÉTODOS}

Con base en las preguntas antes mencionadas se realizó una revisión de la literatura en inglés y español publicada en las base de datos Medline vía PubMed utilizando los siguientes términos MESH: "Hereditary breast and ovarian cancer syndrome/diagnosis"[Majr] OR "Hereditary breast and ovarian cancer syndrome/genetics"[Majr] OR "Hereditary breast and ovarian cancer syndrome/pathology"[Majr] OR "Hereditary breast and ovarian cancer syndrome/prevention and control”[Majr]. La búsqueda se limitó a artículos en humanos y con fecha de publicación entre el 2005 y el 1 de marzo 2015. Además, se incluyeron por su pertinencia y relevancia artículos encontrados en las bases de datos ScienceDirect y SciELO. Se buscaron ensayos clínicos y estudios observacionales y de revisión o guías de práctica clínica. Se excluyeron los artículos en los que la metodología no fuera clara en cuanto a los criterios de inclusión, exclusión de pacientes o el método de estudio genético. Se extrajo la información pertinente a través de la producción de matrices para clasificar y combinar la información de los artículos revisados.

\section{RESULTADOS}

A través de la búsqueda en PubMed se obtuvieron 56 artículos, de los cuales un total de 45 aportaron evidencia relacionada con SCHMO; de estos, 12 fueron descriptivos, 11 experimentales, 6 de cohortes, 1 de casos y controles, 14 de revisión y 1 guía clínica. En ScienceDirect y SciELO se encontraron 7 artículos; de estos, 5 artículos fueron de revisión y 2 descriptivos. Además, se incluyeron 4 artículos de fuentes no ligadas a estas bases de datos por su aporte y peso de información, 1 artículo descriptivo, 1 artículo de revisión, 2 guías clínicas, 1 reporte de prevención del Instituto Americano para la Investigación en Cáncer y 2 entradas de la base de datos OMIM.

\section{1. ¿Qué son los genes BRCA?}

Los genes BRCA1 y BRCA2 (siglas del inglés Breast Cancer Type 1 o 2 gene) pertenecen a la familia de genes supresores de tumores. Si bien estos genes y sus proteínas son diferentes, interactúan con funciones críticas en los mecanismos de reparación del ADN en el ciclo celular, controlan la proliferación celular y mantienen la estabilidad genómica. Específicamente, son inhibidores selectivos del crecimiento de células ováricas y mamarias (12) y su expresión está regulada por estrógenos (15). Mutaciones en estos genes están relacionadas con diferentes tipos cáncer, especialmente de mama y ovario. Tienen un patrón de herencia autosómico dominante $(16,17)$.

\section{2. ¿Qué tan frecuente es la mutación del gen BRCA?}

En la población general, la prevalencia estimada de ser portador de la mutación en BRCA1 y BRCA2 al nacer es 0,11 y 0,12\% respectivamente. Entre los pacientes con cáncer de mama diagnosticados antes de los 50 años de edad, la prevalencia es de 
3,1\% para BRCA1 y 3,0\% para BRCA2. Si el diagnóstico de cáncer de mama se realizó entre los 50 y los 69 años de edad, la prevalencia de la mutación es menor con $0,49 \%$ para BRCA 1 y $0,84 \%$ para BRCA 2. Para el caso de la población general, sin patologías y menores de 70 años, la prevalencia de las mutaciones en los genes BRCA1 y BRCA2 es de 1,3 y $1,5 \%$ respectivamente (18).

Se han encontrado cientos de diversas mutaciones en estos genes; sin embargo, un número de mutaciones específicas se han observado en ciertas poblaciones, donde la misma mutación se ha encontrado en distintos grupos familiares no relacionados, pudiendo ser rastreados a ancestros comunes, como las mutaciones 187deIAG-5385insC en BRCA1 y 6174deIT en BRCA 2 para los judíos Ashkenazi, con una frecuencia aproximada de 1 en 40 (19).

\section{3. ¿Qué determina la presencia de la mutación del gen?}

Normalmente, la probabilidad de que un gen supresor de tumores como BRCA1 y BRCA2 para el caso de SCHMO pueda mutarse en una célula determinada es baja. En individuos sin riesgo para síndrome de cáncer hereditario se necesitan dos eventos separados a fin de eliminar la funcionalidad del gen responsable de este síndrome (una mutación en el alelo heredado, tanto del padre como de la madre). Por el contrario, cuando una persona hereda una mutación en cualquiera de estos dos genes de susceptibilidad, el primer evento (first hit) ya está dado, por lo cual el paciente depende de la segunda copia (back up copy) del gen mutado presente en el cromosoma homólogo para mantener la función normal de la célula. Estos pacientes están en un alto riesgo de sufrir el segundo evento (second hit), eliminando la copia de respaldo y, por ende, perdiendo por completo la función del gen afectado (20).

La probabilidad de que estos eventos independientes ocurran en cada alelo del gen supresor de tumores es considerada extremadamente baja; es por esto que a diferencia de los casos de cáncer no sindromático, el ser portador de una mutación en uno de los genes relacionados con síndromes de cáncer hereditario representa un alto riesgo de desarrollar de cáncer (7).

La herencia de mutaciones en los genes BRCA es autosómica dominante, caracterizándose por una transmisión vertical donde la enfermedad se presenta en cada generación. El portador de una mutación -tanto hombres como mujeres- tiene un $50 \%$ de riesgo de transmitir la mutación a sus hijos (21).

\section{4. ¿Cuál es el riesgo de desarrollar cáncer de mama y ovario para los pacientes con mutaciones en BRCA?}

Los genes relacionados con los síndromes de cáncer hereditario pueden estar directa o indirectamente asociados con el mantenimiento de la integridad genómica. Sus funciones abarcan diversos procesos vitales para la célula, por lo cual, ante la presencia de una mutación, se genera una inestabilidad genética que permite la acumulación de mutaciones que con el tiempo progresan a cáncer (22-24).

Las portadoras de una mutación en los genes BRCA1 y BRCA2 tienen un riesgo importante de desarrollar cáncer de mama/ ovario a temprana edad, el cual aumenta considerablemente con el avance de la edad y difiere según en qué gen mutado (24-26). Para el caso de cáncer de mama, una mujer de 20 años con mutación en el gen BRCA1 va a tener un 1-2\% de riesgo de desarrollar cáncer en los próximos 10 años, ese riesgo es similar al de portadoras del gen BRCA2 mutado en quienes es de 1-1,5\%. Ese riesgo es mucho mayor en mujeres de 40 años con la misma mutación, llegando a desarrollar cáncer de mama entre $16-25$ y $12-19 \%$ en portadoras de BRCA1 y BRCA2 respectivamente, en los siguientes 10 años. Una situación similar se presenta en el caso de riesgo de cáncer de ovario, en que la probabilidad aumenta con la edad; las mujeres de 20 años con mutaciones en los genes BRCA1 o BRCA2 presentan un riesgo del $1-2 \mathrm{y} \leq 1 \%$ respectivamente de 
desarrollar esta patología a 10 años; y a los 40 años ese mismo riesgo aumenta a 5-9 y 1-3\% $(27,28)$. Sin embargo, el riesgo está afectado por el número de años que se ha vivido sin cáncer al momento de hacerse el diagnóstico de mutaciones en los BRCA; así, el riesgo de desarrollar cáncer a lo largo de la vida de una mujer que a los 50 años se le hace el hallazgo genético es menor que para una mujer a la que se le hizo a los 20 años $(27,28)$. Cabe resaltar, entonces, que en ambos casos el paso del tiempo y de la edad aumenta el riesgo de desarrollar cáncer; sin embargo, el riesgo a los 50 años para una mujer que consulta a los 40 años de edad se considera menor que el de una mujer que consulta a los 20 años, ya que la favorece el número de años que ha vivido sin desarrollar cáncer $(25,26)$

Un estudio de cohorte en individuos con mutaciones BRCA1-BRCA2, realizado en el 2013 en Reino Unido ( $\mathrm{N}=1887)$, determinó que el riesgo acumulado para los 70 años de desarrollar cáncer de seno u ovario fue de entre 59 y $60 \%$ para BRCA1 y de y 16,5 a $55 \%$ para BRCA2 respectivamente. Igualmente, el riesgo de desarrollo contralateral en la población diagnosticada con cáncer unilateral $(\mathrm{N}$ = 651) para los 70 años fue estimado en $83 \%$ para portadores BRCA1 y $62 \%$ para BRCA2 (27).

Para cáncer epitelial de ovario, las mutaciones de línea germinal en BRCA1 y BRCA2 son responsables de cerca del $10 \%$ de estas neoplasias; un estudio en una muestra de 977 pacientes con cáncer de ovario invasivo mostró que 75 eran portadoras de mutación en BRCA1 y 54 en BRCA2, para una frecuencia total de mutación de 13,2\% (IC $95 \%$ : 11,2-15,5) (28).

\section{5. ¿Varía el tipo de cáncer de seno según la mutación?}

Las manifestaciones morfológicas y patológicas de las neoplasias malignas de mama y ovario varían según si están asociadas a mutaciones en BRCA1 y BRCA2, si son derivados de cánceres no hereditarios (29) y, además, van a depender de su presentación histopatológica, la cual puede ser: 1) positiva para uno o todos los receptores (estrógenos, progesterona, HER-2) o una neoplasia con características triple negativas, es decir, para estos tres receptores. Las características hitopatológicas tienen la propiedad de ser indicadores de riesgo, por lo cual es un elemento importante para tener en cuenta a la hora de plantear un manejo adecuado en el tratamiento de la enfermedad, ya que los tumores triple negativos (TN) son más agresivos, con mayor probabilidad de generar metástasis y reaparición en instancias posteriores al tratamiento, comparativamente con los tumores positivos, obligando un abordaje diferente del paciente, porque los TN no responden a la hormonoterapia con fármacos dirigidos a bloquear estos receptores, ya que no los expresan en igual medida que otros tipos de tumores.

Los cánceres de mama asociados a la mutación del gen BRCA1 son con frecuencia negativos para la presencia de receptores de estrógeno, progesterona, y la sobreexpresión de HER-2/Neu (triple negativo) (30-33). El $90 \%$ de los tumores debidos a mutaciones en BRCA1 son triple negativos por inmunohistoquímica (19); además, en pacientes con tumores TN, la probabilidad de estar ligados a mutaciones BRCA1 es mayor que en las clasificadas como NO triple negativo, con un $\mathrm{RR}=5,65$ (IC $95 \%$ : 4,15-7,69) (34); sin embargo, se desconoce la proporción exacta de tumores triple negativos que poseen mutaciones en BRCA1 (20). Por otro lado, aquellos fenotipos TN ligados a mutación BRCA1 han mostrado edades de aparición más temprana que otros no ligados a mutación (35). Los tumores debido a mutaciones en BRCA2, al contrario que los de BRCA1, son positivos para receptores de estrógeno y progesterona, asemejándose a los tumores de cánceres no hereditarios $(20,29,30,33,36)$.

Los cánceres de mama asociados a la mutación del gen BRCA1 se relacionan con una incidencia del $13 \%$ de carcinoma medular y carcinoma ductal invasivo frente a $5 \%$ de los cánceres no hereditarios (37). Yip et al., en un estudio con 152 pacientes, mostraron que los SCHMO asociados a mutaciones en el gen BRCA1 se caracterizan por presentar tumores de estadios más avanzados grado 3 en 69,2\%, comparado con el $40 \%$ en los portadores BRCA2 y 
37,5\% en los pacientes con cánceres de mama no sindromáticos (38). Los pacientes con mutación en BRCA2 y cáncer de mama tienen mejor pronóstico que aquellos con mutaciones en BRCA1 (29).

En el caso de los subtipos de cáncer de ovario, se encontró que aquellos que estaban asociados a mutaciones en BRCA1 y BRCA2 por lo general eran tumores serosos (63\%), de estadios más avanzados (70\%) $(13,39-42)$. Por su parte, los tumores mucosos y los limítrofes de ovario ocurren con menor frecuencia en pacientes portadores de mutaciones en los genes BRCA $(39,43,44)$.

\section{6. ¿Cuál es la importancia de la consejería genética para los pacientes con sospecha o diagnóstico de SCHMO?}

Los pacientes con sospecha o diagnóstico de algún síndrome de cáncer hereditario, o específicamente SCHMO, deben ser manejados por un equipo multidisciplinario que incluya a un oncólogo, que puede ser cirujano, ginecólogo u oncólogo clínico; un psicólogo o psiquiatra y un genetista médico (45). El asesoramiento genético busca educar a los pacientes en las bases genéticas del síndrome de cáncer hereditario, su heredabilidad, las implicaciones de realizarse las pruebas moleculares, solicitar las pruebas en los casos necesarios e interpretar los resultados, solicitar pruebas moleculares a familiares cuando corresponda; en algunos casos, realizar recomendaciones sobre los planes de manejo (5, 46-48).

La visita al genetista médico debería anteceder a la solicitud de las pruebas moleculares con la finalidad de que el paciente tenga toda la información de las implicaciones si el diagnóstico molecular fuera positivo (49, 50). Es importante que los pacientes tengan presente el riesgo aumentado que tienen de desarrollar cáncer según la edad y la mutación que porten $(6,51)$.

\section{7. ¿Cuál es la importancia y cómo hacer el diagnóstico y manejo de los síndromes de cáncer hereditario?}

Reconocer que una neoplasia puede ser parte de un síndrome de cáncer hereditario puede llevar a la detección temprana e incluso a la prevención de casos de cáncer en el mismo paciente afectado y sus familiares (45).

Para SCHMO, las pruebas genéticas en una muestra de sangre o saliva pueden identificar una mutación en el gen BRCA1 o BRCA2 (52); sin embargo, la historia familiar sigue siendo esencial y el primer paso para identificar clínicamente a las personas en riesgo de ser portadoras de mutaciones en los genes BRCA. La construcción de heredogramas de al menos tres generaciones consecutivas que incluyan a todos los familiares (sanos y afectados), causas de muerte, los tipos de cáncer y las edades de diagnóstico, es indispensable para sospechar e identificar los síndrome de cáncer hereditario y justificar la solicitud de pruebas genéticas $(45,53)$.

Los criterios diagnósticos para determinar a qué pacientes se les ordenan pruebas genéticas y moleculares SCHMO están descritos en la guía de la NCCN del año 2015 (54) (figuras 1 y 2). Si se cumple con uno o más de los criterios descritos, se debe considerar la realización de las pruebas moleculares para determinar si se es portador de las mutaciones en BRCA1 / BRCA2 para SCHMO.

Tras determinar la elegibilidad para las pruebas, se debe escoger la prueba molecular más adecuada para la identificación de la mutación en sospecha. El diagnóstico de síndrome de cáncer hereditario se confirma con una prueba positiva para alguna mutación en los genes de susceptibilidad para cáncer. En caso de ser positivo, se debe ofrecer a los familiares en riesgo la realización de la misma prueba genética a fin de determinar si son portadores o no de la misma mutación (21).

En caso de que las pruebas para mutaciones en BRCA1 / BRCA2 salgan positivas, o no se realicen dichas pruebas, pero el paciente pertenezca a una familia con una mutación en estos genes conocida, se debe dar el mismo manejo al paciente (tabla 1). En los casos donde no se conoce una mutación deletérea familiar y no se realiza la prueba molecular, aunque se cumplan los criterios para la realización de la misma, se debe realizar consejería genética 
individualizada de acuerdo con la historia familiar y personal de cada paciente (54).

Es importante resaltar que la predisposición genética a desarrollar cáncer de mama/ ovario no solo está asociada con mutaciones en los genes BRCA1 y BRCA2, de manera que ante un resultado negativo en las pruebas que evalúan estos genes en un paciente con una historia familiar fuerte de cáncer, el ginecólogo, en conjunto con el genetista médico, deben considerar realizar otras pruebas moleculares para evaluar otros genes implicados y diagnosticar otros síndromes de cáncer hereditario que incluyen cáncer de seno y ovario como Li-Fraumeni, síndrome de Cowden, entre otros (54). En principio, las pruebas genéticas para diagnosticar los síndromes mencionados se deben realizar en un familiar del paciente que consulta que ya haya tenido cáncer $(45,54-57)$.

\section{8. ¿Qué interpretación debo dar a un resultado positivo?}

Para el caso de los portadores con mutación en el gen BRCA1 el riesgo acumulado promedio para los 70 años de edad de desarrollar cáncer de mama es de $57 \%$ y para cáncer de ovario de $40 \%$ (6). Los portadores de la mutación en el gen BRCA2 presentan un riesgo acumulado para los 70 años de edad de desarrollar cáncer de mama en un 49\% y cáncer de ovario en un $18 \%$ (49). Pacientes con cáncer de mama unilateral y portadoras de mutaciones en BRCA1 y 2 tienen un riesgo de desarrollar cáncer en el otro seno de 35 a $43 \%$ (49). Así, el paciente y el equipo multidisciplinario pueden discutir y decidir sobre la realización de mastectomía o salpingooforectomía profiláctica $(5,29)$, las cuales han demostrado reducir el riesgo de desarrollar cáncer de mama y ovario hasta en un $90 \%$ (58).

\section{RESOLUCIÓN DEL ESCENARIO}

La paciente trae a los 15 días el resultado, el cual es positivo para mutación del gen BRCA 1; usted le indica que hay que realizar una junta multidisci- plinaria con el genetista, el cirujano y el psicólogo para decidir la mejor conducta. La paciente, quien está muy angustiada, pregunta:

\section{1. ¿Tengo cáncer?}

El resultado de BRCA 1 o 2 positivo no indica que usted tenga cáncer. Sin embargo, debe hacerse mamografía y una resonancia magnética nuclear de mamas anualmente para descartar lesiones sugestivas (54). Usted en el momento no tiene hallazgos que hagan diagnóstico de cáncer.

\section{2. ¿Me va a dar cáncer en el futuro?}

Usted tiene un alto riesgo de presentar cáncer de mama u ovario a lo largo de su vida. De 100 mujeres que tienen BRCA1 positivo, el $57 \%$ desarrollaran cáncer de seno y el $40 \%$ cáncer de ovario a los 70 años (6).

\section{3. ¿Me debo quitar los senos?}

El caso será discutido en una junta médica para hacerle propuestas concretas de seguimiento con exámenes o considerar si se le propondrá como una opción la mastectomía (cirugía de retirar los senos y reconstrucción) o la salpingooforectomía (cirugía para extraer las trompas y los ovarios) profiláctica. La realización de una mastectomía profiláctica bilateral en casos de alto riesgo, como las pacientes con cánceres hereditarios es una opción recomendada por la "Guía de manejo de la Sociedad Americana de Oncología Clínica para la supervivencia de los pacientes con cáncer” (59). Basados en los riesgos explicados usted debe tomar la decisión con ayuda de su médico (54).

\section{4. ¿Qué pasa si me dejo los senos y me da cáncer de seno?}

Si usted no se quita los senos y se hace los exámenes de seguimiento como mamografía e IRM anuales, es muy probable que si le da cáncer se detecte en un estadio temprano y tenga un tratamiento oportuno con resultados favorables. 
Figura 1

Criterios para determinar pacientes candidatos a pruebas moleculares de SCHMO según su riesgo

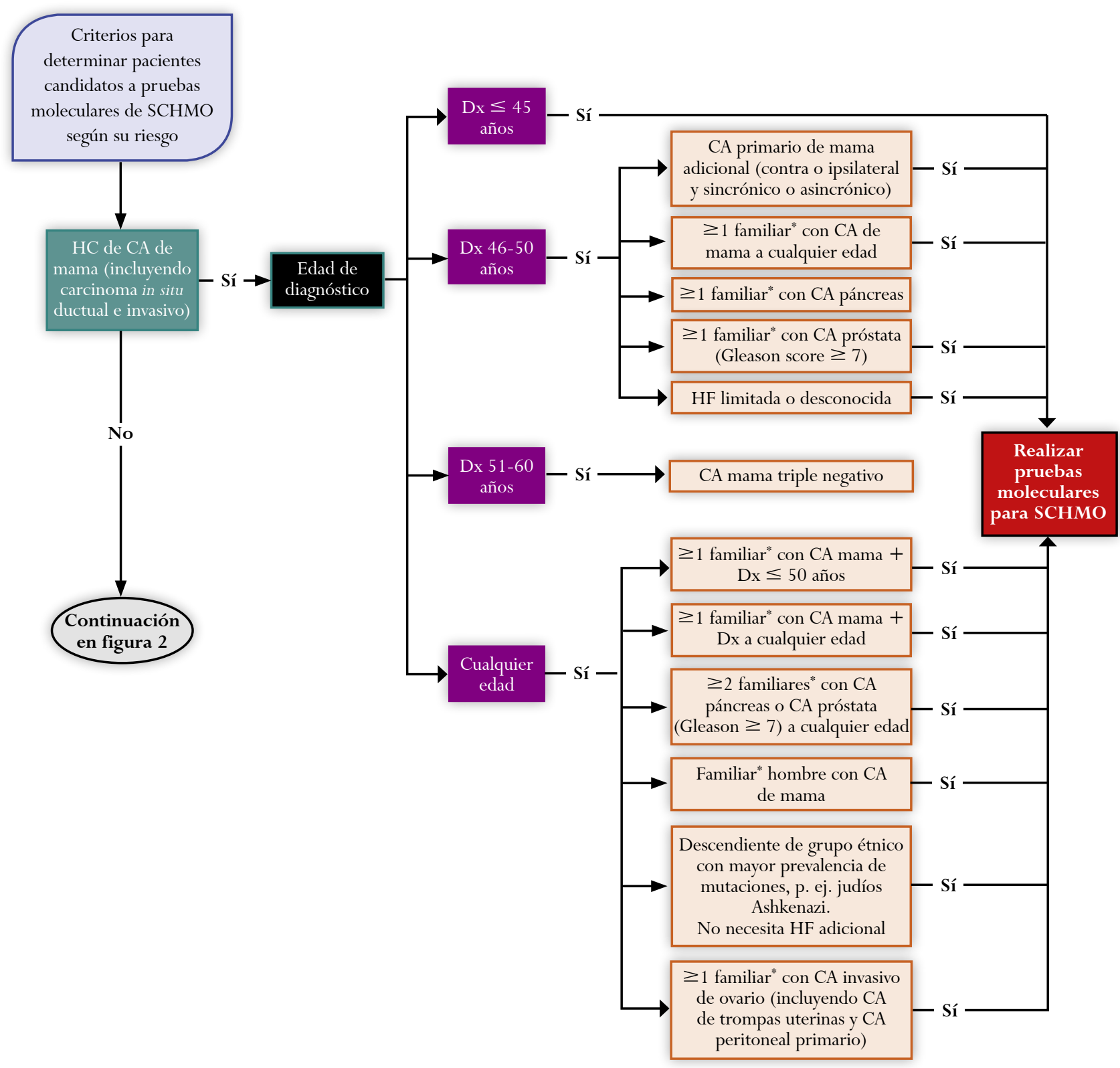

"Familiar: familiar hasta tercer grado del mismo lado de la familia.

HF: historia familiar

HC: historia clínica

CA: cáncer de mama 
Figura 2.

Continuación de criterios para determinar pacientes candidatos a pruebas moleculares de SCHMO según su riesgo

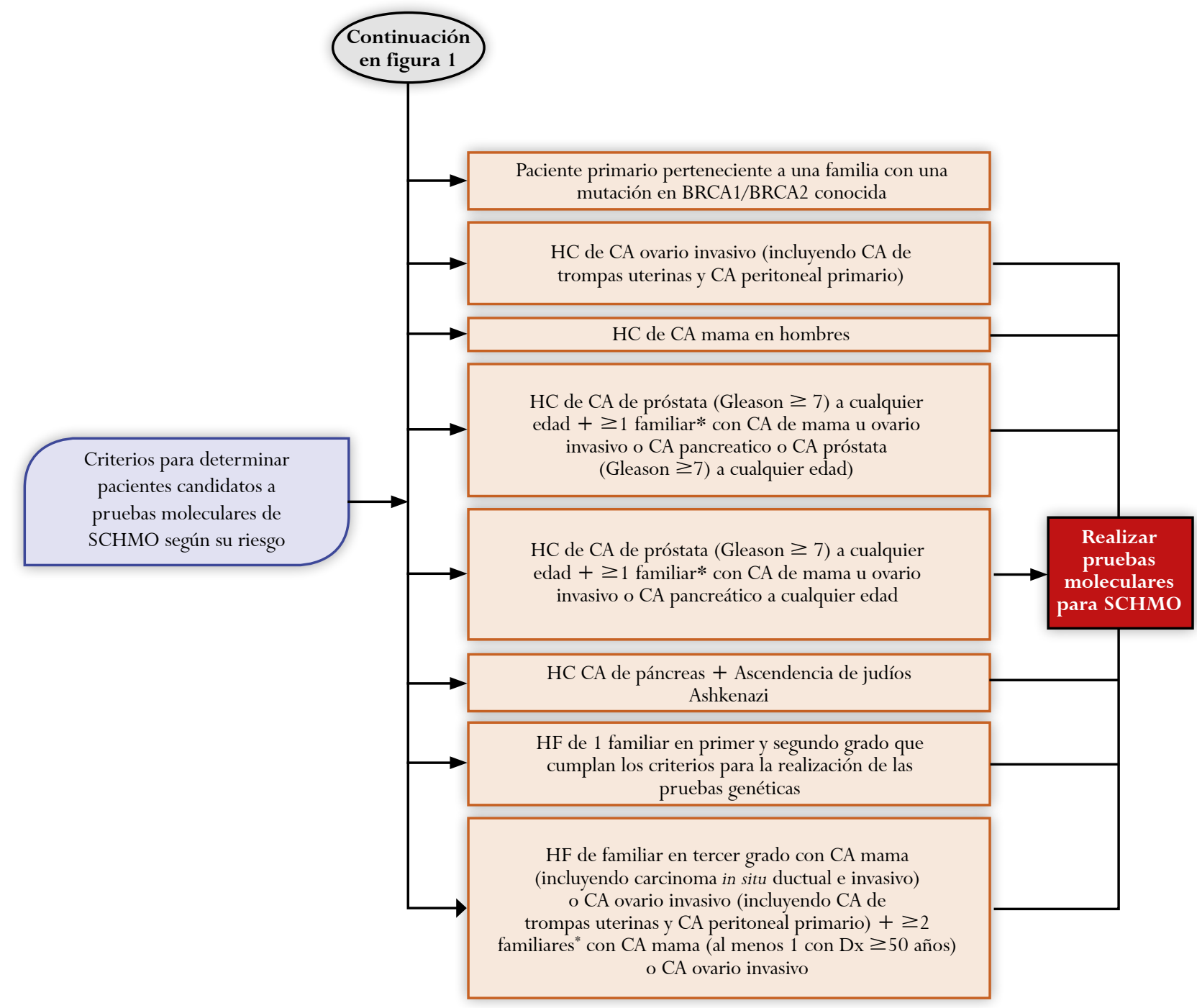

"Familiar: familiar hasta tercer grado del mismo lado de la familia.

HF: historia familiar

HC: historia clínica

CA: cáncer de mama 


\begin{tabular}{|c|c|c|c|}
\hline Edad (años) & Procedimiento/Examen & Frecuencia & Observaciones \\
\hline$>18$ & Autoexamen de mama & Mensual & $\begin{array}{l}\text { Realizar idealmente en los últimos días } \\
\text { de la menstruación }\end{array}$ \\
\hline$\geq 25$ & Examen clínico de mamas & $\begin{array}{l}\text { Cada 6-12 } \\
\text { meses }\end{array}$ & \\
\hline Cualquier edad & $\begin{array}{l}\text { Educación sobre los signos y } \\
\text { síntomas de cáncer asociado a } \\
\text { mutaciones de los genes BRCA }\end{array}$ & & \\
\hline \multicolumn{4}{|l|}{ Tamizaje de mama* } \\
\hline \multirow[b]{3}{*}{$25-29$} & $\begin{array}{l}\text { Resonancia magnética (RM) } \\
\text { de mamas }\end{array}$ & Anual & $\begin{array}{l}\text { Idealmente día } 7-15 \text { del ciclo menstrual } \\
\text { en mujeres premenopáusicas }\end{array}$ \\
\hline & Mamografía & Anual & Si la RM no está disponible \\
\hline & $\begin{array}{l}\text { Manejo individualizado basado } \\
\text { en historia familiar de CA de } \\
\text { mama diagnosticado antes de los } \\
25 \text { años }\end{array}$ & & \\
\hline $\begin{array}{l}30-75 \text { o } \\
\text { cualquier edad }+ \\
\text { mujeres con SCHMO } \\
\text { en tratamiento para CA } \\
\text { de mama }\end{array}$ & Mamografía y RM de mamas & Anual & $\begin{array}{l}\text { RM de mamas: realizar idealmente } \\
\text { día } 7-15 \text { del ciclo menstrual en mujeres } \\
\text { premenopáusicas } \\
\text { En mujeres con SCHMO y CA de } \\
\text { mama se realiza el tamizaje para el } \\
\text { tejido mamario sano }\end{array}$ \\
\hline 75 & & & $\begin{array}{l}\text { Manejo se realiza tras evaluación } \\
\text { individual }\end{array}$ \\
\hline \multicolumn{4}{|l|}{ Tamizaje cáncer de ovario } \\
\hline $30-35$ & Ecografía transvaginal & & Como método de tamizaje no tiene \\
\hline Cualquier edad & CA-125 sérico & & $\begin{array}{l}\text { recomendación. Se utiliza a discreción } \\
\text { del clínico }\end{array}$ \\
\hline \multicolumn{4}{|c|}{ Tratamientos para reducción del riesgo de CA en pacientes con $\mathrm{SCHMO}^{* *}$} \\
\hline $35-40$ & $\begin{array}{l}\text { Salpingooforectomía para } \\
\text { reducción de riesgo tras haber } \\
\text { tenido hijos }\end{array}$ & & $\begin{array}{l}\text { Ideal consultar con ginecólogo oncólogo, } \\
\text { más consejería (deseos reproductivos, } \\
\text { riesgo de la extensión del cáncer, grado de } \\
\text { protección para cáncer de mama y ovario, } \\
\text { manejo de síntomas de menopausia, } \\
\text { terapia de reemplazo hormonal) } \\
\text { Esta medida como terapia única NO es } \\
\text { efectiva }\end{array}$ \\
\hline
\end{tabular}

* A todas las pacientes se les debe ofrecer consejería tanto genética como de manejo, con el fin de permitirles tomar una decisión informada sobre su manejo clínico.

${ }^{* *}$ Los tratamientos de reducción de riesgo con procedimientos quirúrgicos deben incluir consejería acerca del grado de protección que ofrece el procedimiento, posibilidades de reconstrucción y riesgos. 


\section{5. ¿Qué otros exámenes debo realizar en este caso?}

No es necesario realizar otros exámenes en la paciente dado que no se encontraron síntomas o signos sugestivos de patología en la historia clínica.

\section{CONCLUSIÓN}

El ginecoobstetra debe identificar pacientes con riesgo de presentar el síndrome de cáncer hereditario de mama y ovario, explicar a los pacientes la importancia de la realización de la pruebas moleculares de los genes BRCA1 y BRCA2, y participar en equipos multidisciplinarios que, además, deben incluir al genetista, cirujano, oncólogos y al paciente para la toma de decisiones medicas según los resultados.

\section{REFERENCIAS}

1. Bolufer P, Munárriz B, Santaballa A, Velasco E, Lerma E, Barragán E. Mutaciones en BRCA1 y BRCA2 en pacientes con historia familiar de cáncer de mama. Med Clin (Barc). 2005;124:10-2.

2. Wooster R, Bignell G, Lancaster J, Swift S, Seal S, Mangion J, et al. Identification of the breast cancer susceptibility gene BRCA2. Nature. 1995;378:78992. doi:10.1038/378789a0.

3. Claus EB, Schildkraut J, Iversen ES, Berry D, Parmigiani G. Effect of BRCA1 and BRCA2 on the association between breast cancer risk and family history. J Natl Cancer Inst. 1998;90:1824-9. doi:10.1093/jnci/90.23.1824.

4. Arteaga Caiza JH, Caiza A, Huñis AP. El cáncer de mama hereditario. Médico Interamericano. 2004;1-4.

5. Stan DL, Shuster LT, Wick MJ, Swanson CL, Pruthi S, Bakkum-Gamez JN. Challenging and complex decisions in the management of the BRCA mutation carrier. J Womens Health (Larchmt). 2013;22:82534. doi:10.1089/jwh.2013.4407.

6. Christinat A, Pagani O. Practical aspects of genetic counseling in breast cancer: lights and shadows. Breast. 2013;22:375-82. doi:10.1016/j.breast.2013.04.006.

7. Darbary H, Stoler DL, Anderson GR. Family cancer syndromes: inherited deficiencies in systems for the maintenance of genomic integrity. Surg Oncol Clin N Am. 2009;18:1-17. doi:10.1016/j.soc.2008.08.001.

8. Piñeros M, Ferlay J, Murill R. Incidencia estimada de cáncer en Colombia a nivel departamental y nacional. Salud Publica Mex. 2006;48:455-65.

9. Torres D, Rashid MU, Gil F, Umana A, Ramelli G, Robledo JF, et al. High proportion of BRCA1/2 founder mutations in Hispanic breast/ovarian cancer families from Colombia. Breast Cancer Res Treat. 2007;103:225-32. doi:10.1007/s10549-006-9370-1.

10. American Institute for Cancer Research. Ovarian Cancer 2014. Report Food, Nutrition, Physical Activity, and the Prevention of Ovarian Cancer. Am Inst Cancer Res; 2014.

11. van der Groep P, van der Wall E, van Diest PJ. Pathology of hereditary breast cancer. Cell Oncol. 2011;34:7188. doi:10.1007/s13402-011-0010-3.

12. Gallón Villegas LJ. Cáncer de mama asociado a mutaciones genéticas de los BRCA 1 y 2 . Rev CES Med. 2012;26:185-99.

13. Pal T, Permuth-Wey J, Betts JA, Krischer JP, Fiorica J, Arango $\mathrm{H}$, et al. BRCA1 and BRCA2 mutations account for a large proportion of ovarian carcinoma cases. Cancer. 2005;104:2807-16. doi:10.1002/cncr.21536.

14. Garber JE, Offit K. Hereditary cancer predisposition syndromes. J Clin Oncol. 2005;23:276-92. doi:10.1200/JCO.2005.10.042.

15. Jensen RA, Thompson ME, Jetton TL, Szabo CI, van der Meer R, Helou B, et al. BRCA1 is secreted and exhibits properties of a granin. Nat Genet. 1996;12:303-8. doi:10.1038/ng0396-303.

16. OMIMEntry - \# 612555 - BREAST-OVARIANCANCER, FAMILIAL, SUSCEPTIBILITY TO, 2; BROVCA2. s. f. [Visitado 2014 Oct 7]. Disponible en: http://www.omim. org/entry/612555? search=BRCA2 \&highlight=brca2

17. OMIM Entry - \# 604370 - BREAST-OVARIAN CANCER, FAMILIAL, SUSCEPTIBILITY TO, 1; BROVCA1 s. f. [Visitado 2014 Oct 7]. http:/www.omim. org/entry/604370? search = BRCA1\&highlight $=$ brca1 
18. Peto J, Collins N, Barfoot R, Seal S, Warren W, Rahman $\mathrm{N}$, et al. Prevalence of BRCA1 and BRCA2 Gene Mutations in Patients With Early-Onset Breast Cancer. JNCI J Natl Cancer Inst. 1999;91:943-9. doi:10.1093/ jnci/91.11.943.

19. Metcalfe KA, Poll A, Royer R, Llacuachaqui M, Tulman A, Sun P, et al. Screening for Founder Mutations in BRCA1 and BRCA2 in Unselected Jewish Women. J Clin Oncol. 2009;28:387-91. doi:10.1200/JCO. 2009.25.0712.

20. Margarit S. Cáncer hereditario de mama. Rev Chil Radiol. 2008;14. doi:10.4067/S0717-9308200 8000300006.

21. Hamilton R. Genetics: breast cancer as an exemplar. Nurs Clin North Am. 2009;44:327-38. doi:10.1016/j. cnur.2009.06.004.

22. Markowitz S, Wang J, Myeroff L, Parsons R, Sun L, Lutterbaugh J, et al. Inactivation of the type II TGFbeta receptor in colon cancer cells with microsatellite instability. Science. 1995;268:1336-8. doi:10.1126/ science. 7761852

23. Feuer EJ, Wun L-M, Boring CC, Flanders WD, Timmel MJ, Tong T. The Lifetime Risk of Developing Breast Cancer. JNCI J Natl Cancer Inst. 1993;85:8927. doi:10.1093/jnci/85.11.892.

24. Bayraktar S, Glück S. Systemic therapy options in BRCA mutation-associated breast cancer. Breast Cancer Res Treat. 2012;135:355-66. doi:10.1007/ s10549-012-2158-6.

25. Chen S, Parmigiani G. Meta-analysis of BRCA1 and BRCA2 penetrance. J Clin Oncol. 2007;25:1329-33. doi:10.1200/JCO.2006.09.1066.

26. Meaney-Delman D, Bellcross CA. Hereditary breast/ ovarian cancer syndrome: a primer for obstetricians/ gynecologists. Obstet Gynecol Clin North Am. 2013;40:475-512. doi:10.1016/j.ogc.2013.05.009.

27. Mavaddat N, Peock S, Frost D, Ellis S, Platte R, Fineberg E, et al. Cancer risks for BRCA1 and BRCA2 mutation carriers: results from prospective analysis of embrace. J Natl Cancer Inst. 2013;105:812-22. doi:10.1093/jnci/djt095.

28. Risch HA, McLaughlin JR, Cole DEC, Rosen B, Bradley L, Fan I, et al. Population BRCA1 and BRCA2 mutation frequencies and cancer penetrances: a kin- cohort study in Ontario, Canada. J Natl Cancer Inst. 2006;98:1694-706. doi:10.1093/jnci/djj465.

29. Long KC, Kauff ND. Hereditary ovarian cancer: recent molecular insights and their impact on screening strategies. Curr Opin Oncol. 2011;23:526-30. doi:10.1097/CCO.0b013e3283499da9.

30. Lakhani SR, van der Vijver MJ, Jacquemier J, Anderson TJ, Osin PP, McGuffog L, et al. The pathology of familial breast cancer: predictive value of immunohistochemical markers estrogen receptor, progesterone receptor, HER-2, and p53 in patients with mutations in BRCA1 and BRCA2. J Clin Oncol. 2002;20:2310-8.

31. Lakhani SR, Reis-Filho JS, Fulford L, Penault-Llorca F, van der Vijver M, Parry S, et al. Prediction of BRCA1 status in patients with breast cancer using estrogen receptor and basal phenotype. Clin Cancer Res. 2005;11:5175-80. doi:10.1158/1078-0432. CCR-04-2424.

32. Sharma P, Klemp JR, Kimler BF, Mahnken JD, Geier LJ, Khan QJ, et al. Germline BRCA mutation evaluation in a prospective triple-negative breast cancer registry: implications for hereditary breast and/ or ovarian cancer syndrome testing. Breast Cancer Res Treat. 2014;145:707-14. doi:10.1007/s10549-0142980-0.

33. Konstantopoulou I, Tsitlaidou M, Fostira F, Pertesi M, Stavropoulou A-V, Triantafyllidou O, et al. High prevalence of BRCA1 founder mutations in Greek breast/ovarian families. Clin Genet. 2014;85:36-42. doi:10.1111/cge. 12274 .

34. Tun NM, Villani G, Ong K, Yoe L, Bo ZM. Risk of having BRCA1 mutation in high-risk women with triple-negative breast cancer: a meta-analysis. Clin Genet. 2014;85:43-8. doi:10.1111/cge.12270.

35. González-Angulo AM, Timms KM, Liu S, Chen H, Litton $\mathrm{JK}$, Potter J, et al. Incidence and outcome of BRCA mutations in unselected patients with triple receptornegative breast cancer. Clin Cancer Res. 2011;17:1082-9. doi:10.1158/1078-0432.CCR-10-2560.

36. Chappuis PO, Nethercot V, Foulkes WD. Clinicopathological characteristics of BRCA1- and BRCA2related breast cancer. Semin Surg Oncol. 2000;18:287-95. 
37. Stratton MR. Pathology of familial breast cancer: Differences between breast cancers in carriers of BRCA1 or BRCA2 mutations and sporadic cases. Lancet. 1997;349:1505-10. doi:10.1016/S01406736(96)10109-4.

38. Yip CH, Taib NA, Choo WY, Rampal S, Thong $\mathrm{MK}, \mathrm{vTeo} \mathrm{SH}$. Clinical and pathologic differences betweenvBRCA1-, BRCA2-, and non-BRCAassociated breast cancers in a multiracial developing country. World J Surg. 2009;33:2077-81. doi:10.1007/ s00268-009-0146-8.

39. Palacios J, Honrado E, Osorio A, Cazorla A, Sarrió D, Barroso A, et al. Immunohistochemical characteristics defined by tissue microarray of hereditary breast cancer not attributable to BRCA1 or BRCA2 mutations: differences from breast carcinomas arising in BRCA1 and BRCA2 mutation carriers. Clin Cancer Res. 2003;9:3606-14.

40. Boyd J, Sonoda Y, Federici MG, Bogomolniy F, Rhei E, Maresco DL, et al. Clinicopathologic features of BRCA-linked and sporadic ovarian cancer. JAMA. 2000;283:2260-5.

41. Shaw PA, McLaughlin JR, Zweemer RP, Narod SA, Risch H, Verheijen RHM, et al. Histopathologic features of genetically determined ovarian cancer. Int J Gynecol Pathol. 2002;21:407-11.

42. Werness BA, Ramus SJ, Whittemore AS, GarlinghouseJones K, Oakley-Girvan I, Dicioccio RA, et al. Histopathology of familial ovarian tumors in women from families with and without germline BRCA1 mutations. Hum Pathol. 2000;31:1420-4.

43. Gotlieb WH, Chetrit A, Menczer J, Hirsh-Yechezkel G, Lubin F, Friedman E, et al. Demographic and genetic characteristics of patients with borderline ovarian tumors as compared to early stage invasive ovarian cancer. Gynecol Oncol. 2005;97:780-3. doi:10.1016/j.ygyno.2005.02.022.

44. Lakhani SR, Manek S, Penault-Llorca F, Flanagan A, Arnout L, Merrett S, et al. Pathology of ovarian cancers in BRCA1 and BRCA2 carriers. Clin Cancer Res. 2004;10:2473-81.

45. Dreyer G. Screening for gynaecologic cancers in genetically predisposed women. Best Pract Res Clin
Obstet Gynaecol. 2012;26:267-82. doi:10.1016/j. bpobgyn.2011.11.002.

46. Hamilton RJ, Bowers BJ. The Theory of Genetic Vulnerability: a Roy model exemplar. Nurs Sci Q. 2007;20:254-64. doi:10.1177/0894318407303127.

47. Kenen R, Ardern-Jones A, Eeles R. Living with chronic risk: healthy women with a family history of breast/ ovarian cancer. Health Risk Soc 2003;5:315-31. doi: 10.1080/13698570310001607003.

48. Hallowell N, Foster C, Eeles R, Ardern-Jones A, Watson M. Accommodating risk: responses to BRCA1/2 genetic testing of women who have had cancer. Soc Sci Med. 2004;59:553-65. doi:10.1016/j. socscimed.2003.11.025.

49. Allain DC. Genetic counseling and testing for common hereditary breast cancer syndromes: a paper from the 2007 William Beaumont hospital symposium on molecular pathology. J Mol Diagn. 2008;10:383-95. doi:10.2353/jmoldx.2008.070161.

50. Vidal-Millán S. Cáncer de mama hereditario: identificación y elección de pacientes para estudio molecular de los genes BRCA. Cancerología. 2008; 3:51-61.

51. Torres D, Umaña Á, Robledo JF, Caicedo JJ, Quintero E, Orozco A, et al. Estudio de factores genéticos para cáncer de mama en Colombia. Univ Med Bogotá (Colombia). 2009;297-301.

52. Fries MH, Holt C, Carpenter I, Carter CL, Daniels J, Flanagan J, et al. Guidelines for evaluation of patients at risk for inherited breast and ovarian cancer: recommendations of the Department of Defense Familial Breast/Ovarian Cancer Research Project. Mil Med. 2002;167:93-8.

53. Generalitat Valenciana. Oficina del Plan del Cáncer, Barberá VM. Guía de práctica clínica en cáncer. [Visitado 2016 Ene 21]. Disponible en: http://rua. ua.es/dspace/handle/10045/20253

54. National Comprehensive Cancer Network. NCCN Clinical Practice Guidelines in Oncology (NCCN Guidelines(囚). Genetic/familial high-risk assessment: breast and ovarian, version 2.2015.

55. Frank TS, Deffenbaugh AM, Reid JE, Hulick M, Ward BE, Lingenfelter B, et al. Clinical characteristics of individuals with germline mutations in BRCA1 and 
BRCA2: analysis of 10,000 individuals. J Clin Oncol. 2002;20:1480-90. doi:10.1200/JCO.20.6.1480.

56. Trepanier A, Ahrens M, McKinnon W, Peters J, Stopfer J, Grumet SC, et al. Genetic cancer risk assessment and counseling: recommendations of the national society of genetic counselors. J Genet Couns. 2004;13:83114. doi:10.1023/B:JOGC.0000018821.48330.77.

57. Silva FC, Lisboa BC, Figueiredo MC, Torrezan GT, Santos EM, Krepischi AC, et al. Hereditary breast and ovarian cancer: assessment of point mutations and copy number variations in Brazilian patients. BMC Med Genet. 2014;15:55. doi:10.1186/1471-2350-15-55.
58. Collins IM, Milne RL, Weideman PC, McLachlan S-A, Friedlander ML, Hopper JL, et al. Preventing breast and ovarian cancers in high-risk BRCA1 and BRCA2 mutation carriers. Med J Aust. 2013;199:680-3.

59. Runowicz CD, Leach CR, Henry NL, Henry KS, Mackey HT, Cowens-Alvarado RL, et al. American Cancer Society/American Society of Clinical Oncology Breast Cancer Survivorship Care Guideline. J Clin Oncol. 2016;34:611-35. doi:10.1200/JCO. 2015. 64.3809. 